\title{
EVALUASI PELAKSANAAN PROGRAM PUSAT SUMBER PENDIDIKAN INKLUSIF DI DKI JAKARTA
}

\author{
Indra Jaya ${ }^{1}$ \\ Aip Badrujaman ${ }^{2}$ \\ Anna Suhaenah $\mathbf{S}^{3}$
}

\begin{abstract}
Abstrak
Penelitian ini bertujuan untuk mengetahui efektivitas dan pencapaian implementasi program di pusat sumber daya sekolah pendidikan khusus yang ditetapkan oleh Dinas Pendidikan DKI Jakarta sebagai Pusat Sumber Daya Pendidikan Inklusif. Studi evaluatif ini dilakukan dengan metode mix-methode yang menggabungkan pendekatan kualitatif dan kuantitatif. Evaluasi dilakukan dengan model Context, Input, Process, Product and Outcome (CIPPO). Hasil penelitian menunjukkan bahwa: (1) Seluruh aspek dan indikator komponen konteks telah memenuhi kriteria; (2) Komponen masukan belum memenuhi kriteria; (3) Proses komponen belum memenuhi kriteria; (4) Komponen produk telah memenuhi kriteria; dan (5) Komponen hasil belum memenuhi kriteria.

Kata Kunci: Evaluasi Program, Pusat Sumber, Pendidikan Inklusif
\end{abstract}

\begin{abstract}
This study aims to investigatethe efectiveness and accomplishment of implementing program at resoucse center of schools of special educational needsassigned by Educational Authority of DKI Jakarta as an Inclusive Education Resource Center. This evaluative study was conducted by means of mix-methode combining qualitative and quantitative approaches. The evaluation was carried out by means of Context, Input, Process, Product and Outcome (CIPPO) model. Findings of the study reveal that: (1) All aspects and indicators of context component has met the creteria; (2) Input component has not met the creteria; (3) Component process has not met the creteria; (4) Product component has met the creteria; and (5) Outcome component has not met the creteria.

Keywords: Program Evaluation, Resource Center, Inclusive Education
\end{abstract}

\footnotetext{
${ }^{1}$ Universitas Negeri Jakarta, indrajaya@unj.ac.id

${ }^{2}$ Universitas Negeri Jakarta, aipbadrujaman@unj.ac.id

${ }^{3}$ Universitas Negeri Jakarta, asuhaenah@unj.ac.id
} 



\section{PENDAHULUAN}

Dalam pendidikan, keberagaman yang dialami oleh peserta didik baik keragaman kehidupan sosial maupun keberagaman mental dan fisik merupakan salah satu sasaran pendidikan yang tidak dapat diabaikan. Karena peserta didik merupakan bagian dari warga negara yang memiliki hak yang sama untuk mendapatkan pendidikan yang bermutu.

Penyelenggaraan pendidikan bagi anak berkebutuhan khusus selama ini berbentuk sekolah khusus atau SLB. Namun, pada umumnya, lokasi SLB berada di ibu kota kabupaten. Padahal anak berkebutuhan khusus tersebar hampir di seluruh daerah, baik di kecamatan maupun di desa, akibatnya sebagian anak-anak berkebutuhan khusus terpaksa tidak di sekolahkan karena lokasi SLB jauh dari rumah. Selain itu, Untuk mengatasi masalah tersebut, beberapa pakar pendidikan khusus mulai memperkenalkan sistem baru dalam dunia pendidikan khusus yaitu pendidikan inklusif.

Pada prinsipnya, sistem pendidikan inklusif bertujuan agar semua anak berkebutuhan khusus terlepas dari tingkat dan jenis kebutuhannya harus dididik di kelas secara penuh pada sekolah terdekat bersama dengan teman sebayanya yang normal tanpa memandang keterbatasan ataupun perbedaan yang mungkin ada pada mereka (Mastropieri \& Scruggs, 2010).

Dalam rangka kelancaran pemberian pelayanan pendidikan bagi siswa yang berkelainan/berkebutuhan khusus dan bimbingan bagi guru sekolah inklusif agar mampu memberikan layanan pendidikan yang tepat bagi anak berkebutuhan khusus, pemerintah daerah DKI Jakarta melalui
Dinas Pendidikan menyiapkan program untuk membantu sekolah-sekolah reguler penyelenggara pendidikan inklusif dengan memanfaatkan sekolah luar biasa sebagai pusat sumber (resourse center). Kepala Dinas Pendidikan DKI Jakarta mengeluarkan Surat keputusan Nomor 273/2012 Tentang Penunjukkan Pusat Sumber Pendidikan Inklusif Provinsi DKI Jakarta.

Program ini dapat dibentuk secara khusus, atau memfungsikan Sekolah Luar Biasa (SLB) Negeri atau Swasta yang sudah ada dan memenuhi syarat untuk dipersiapkan menjadi pusat sumber, sehingga mampu melaksanakan fungsi dan peran sebagai Pusat Sumber.

Di DKI Jakarta Sekolah Luar Biasa berjumlah 89 sekolah dengan berbagai kekhususan atau spesialisasi. Dalam rangka kelancaran pemberian pelayanan pendidikan inklusif pada sekolah penyelenggara pendidikan inklusif maka Sekolah Luar Biasa tersebut ditunjuk sebanyak 21 SLB untuk menjadi pusat sumber penyelenggaraan pendidikan khusus.

Namun, setelah 5 (lima) tahun dikeluarkannya surat keputusan penunjukkan pusat sumber pendidikan inklusif. Masih terdapat hal-hal yang pelaksanaannya belum sesuai misalnya, pelaksanaan pembelajaran di sekolah penyelenggara inklusif masih klasikal dan belum adanya program khusus bagi anak, banyak guru sekolah inklusif merasa tidak mampu, dan guru bergantung pada pusat sumber. Selain itu, belum dilakukan evaluasi secara khusus dan menyeluruh untuk mengetahui kendala dan efektifitas pusat sumber sebagai pendukung teknis penyelenggaraan pendidikan inklusif.

Untuk menjawab berbagai masalah di atas, maka perlu diadakan 
evaluasi untuk melihat secara meyakinkan sejauh mana keberhasilan program pusat sumber pendidikan inklusif tersebut. Adapun model evaluasi program yang digunakan untuk mengevaluasi program Pusat Sumber Pendidikan Inklusif yaitu model Context, Input, Procces, Product (CIPP) dari Stufleabeam ditambah dengan komponen Outcome sehingga menjadi CIPPO. Model CIPPO saat ini masih dianggap model yang komprehensif dalam mengevaluasi suatu program yang telah berlangsung lama dan model evaluasi yang memandang bahwa program yang dievaluasi sebagai suatu system.

\section{Pengertian Evaluasi Program}

Evaluasi mempunyai arti yang berhubungan, masing-masing menunjuk pada aplikasi beberapa skala nilai terhadap hasil kebijakan dan program. Menurut Dunn, (2008) "evaluasi refers to the production of information about the value or worth of polisy outcomes. Evaluasi berkaitan dengan produksi informasi mengenai nilai atau manfaat hasil dari suatu kebijakan atau program (Dunn, 2008). Menurut Brinkerhoff \& et. Al (1983) bahwa evaluasi yaitu: (1) proses menentukan sejauh mana tujuan dan sasaran program telah terealisasi, (2) memberikan informasi utuk pengambilan keputusan, perbandingan kinerja dengan patokanpatokan tertentu untuk menentukan apakah terdapat kesenjangan, (4) penilaian tentang harga dan kualitas, (5) ukuran, pilih dan kembangkan ukuran-ukuran yang dengan itu masingmasing tujuan akan ditentukan, dan (6) investigasi sistematis nilai atau kualitas suatu objek. Evaluasi program juga merupakan salah satu jenis obyek dari penelitian evaluasi. Orientasi mendasar dari penelitian evaluasi adalah manfaat penelitian.

Ada tiga alasan mengapa perlu dilakukan evaluasi terhadap suatu program, yaitu: (1) untuk menunjukkan eksistensi dan dana yang dikeluarkan terhadap pencapaian tujuan dan sasaran program yang dilakukan, (2) untuk memutuskan apakah kegiatan atau program yang dilakukan akan diteruskan atau dihapuskan, (3) untuk mengumpulkan informasi bagaimana cara untuk mengembangkan program dimasa mendatang (Kirkpatrick, 2005).

\section{Konsep Pendidikan Inklusif}

Konsep pendidikan inklusif pada mulanya merupakan antitesis dari penyelenggaraan pendidikan luar biasa yang segregatif dan ekslusif. Dalam konsep pendidikan luar biasa atau pendidikan khusus, pendidikan inklusif diartikan sebagai penggabungan penyelenggaraan pendidikan luar biasa dan pendidikan regular dalam satu sistem pendidikan.. Adapun yang dimaksud dengan pendidikan luar biasa adalah pendidikan yang diselenggarakan bagi siswa luar biasa atau berkelainan, baik berkelainan dalam makna memiliki hambatan fisik, sensori, motorik, intelektual, dan/atau social maupun dalam makna dikaruniai keunggulan (gifted dan talented).

Pada prinsipnya, sistem pendidikan inklusif bertujuan agar semua anak berkebutuhan khusus terlepas dari tingkat dan jenis kebutuhannya harus dididik di kelas secara penuh pada sekolah terdekat atau pempatan pada sekolah reguler bersama dengan teman sebayanya yang normal tanpa memandang keterbatasan ataupun perbedaan yang mungkin ada pada mereka (Mastropieri \& Scruggs, 2010; Okongo et al., 2015) 
Dari pendapat tersebut di atas dapat disimpulkan bahwa pendidikan inklusi merupakan sistem penempatan layanan pendidikan bagi anak berkebutuhan khusus disekolah reguler yang ada dilingkungan mereka dan sekolah tersebut dilengkapi dengan layanan pendukung serta pendidikan yang sesuai dengan kemampuan dan kebutuhan anak.

\section{Pusat Sumber Pendidikan Inklusif}

Pusat sumber (resource center) pendidikan inklusif merupakan institusi yang dibentuk dalam rangka pengembangan pendidikan inklusif. Pusat sumber dapat dimanfaatkan oleh semua pihak, khususnya anak berkebutuhan khusus (ABK), orang tua, keluarga, masyarakat, sekolah, pemerintah dan pihak lain yang berkepentingan untuk memperoleh informasi, mendapatkan pelatihan berbagai keterampilan, memperoleh berbagai pengetahuan yang berhubungan dengan penyelenggaraan pendidikan inklusif.

Kementerian Pendidikan dan Kebudayaan mengartikan pusat sumber sebagai suatu tempat atau lembaga yang menyediakan informasi, peralatan, dan dukungan dan pendampingan terhadap sekolah-sekolah reguler yang menyelenggarakan pendidikan inklusif baik secara teknis maupun konsultatif (Kemdikbud, 2014). Layanan dukungan atau pendampingan ini untuk mempermudah dan mengoptimalkan pelaksanaan pendidikan inklusif sehingga terjadi keberlangsungan dan keberhasilan pendidikan bagi anak berkebutuhan khusus.

Program ini dapat dibentuk secara khusus, atau memfungsikan Sekolah Luar Biasa (SLB) Negeri atau Swasta yang sudah ada dan memenuhi syarat untuk dipersiapkan menjadi pusat sumber, sehingga mampu melaksanakan fungsi dan peran sebagai Pusat Sumber.

Berdasarkan pendapat tersebut di atas maka dapat disimpulkan bahwa yang disebut dengan pusat sumber (resource center) adalah lembaga yang memberikan dukungan bagi anak berkebutuhan khusus dalam sistem layanan pendidikan, advokasi, serta aktualisasi diri di manapun anak berada serta layanan terhadap masyarakat dan lembaga lain yang memerlukan.

\section{Evaluasi Model CIPPO}

Model CIPP mengidentifikasi beberapa penyiapan keputusan, diantaranya 4 tipe keputusan pendidikan yaitu: (1) perencanaan keputusan untuk menentukan tujuan, (2) penyusunan keputusan untuk mendesain prosedur pembelajaran, (3) pelaksanaan keputusan digunakan untuk memonitor dan memperbaiki prosedur, (4) mengkaji ulang keputusan untuk menetapkan reaksinya terhadap dampak yang dihasilkan prosedur. ${ }^{4} \mathrm{Ke}$ empat tahapan keputusan inilah yang berhubungan dengan tipe evaluasi yang direkomendasikan yaitu Context, Input, Process, Product, Outcome (CIPPO).

$$
\text { Model CIPPO yang }
$$
disempurnakan dapat dijelaskan secara rinci sebagai berikut:

\section{a. Evaluasi Kontek (Context)}

Evaluasi konteks merupakan menilai atau analisis kebutuhan, permasalahan yang dihadapi, sumberdaya yang dimiliki dan peluang, serta kondisi kontekstual yang relevan dan dinamis untuk membantu dlam mengambil keputusan, menentukan tujuan dan prioritas dn hasil yang diharapkan (Stufflebeam, 2013; 
Popham, 1974). Penyelenggaraan program pusat sumber pendidikan inklusif di Jakarta dianalisis terhadap peraturan kebijakan, analisis berbagai kebutuhan dan tujuan program.

b. Evaluasi Input (Input)

Dalam pengertian umum, input dapat disamakan dengan bahan mentah yang akan diproses. Dalam pelaksanaan suatu program, input dapat diartikan sebagai penggunaan sumber-sumber sistem yang ada di sekolah dapat digunakan untuk memberikan dukungan pada praktek dan strategi harus dipertimbangkan untuk mencapai suatu program (Stufflebeam, D. L. Shinkfield, 2007).

Jadi pada evaluasi input pada program pusat sumber pendidikan inklusif secara menyeluruh, lebih baku, selalu berhubungan dengan staf atau tenaga pendidik, kurikulum, sarana prasarana, keuangan dan kerjasama antar lembaga serta kelengkapan administrasi. Evaluasi input pada program pusat sumber pendidikan inklusif secara menyeluruh yang berhubungan dengan kesiapan SDM (staf atau tenaga pendidik), program, sarana prasarana, keuangan dan kerjasama antar lembaga serta kelengkapan administrasi.

\section{c. Evaluasi Proses (Process)}

Evaluasi proses merupakan evaluasi yang dilakukan untuk melihat apakah pelaksanaan program sesuai dengan strategi yang telah direncanakan. Dengan demikian, evaluasi proses digunakan untuk mengecek pelaksanaan dari apa yang telah direncanakan. Jika ada yang belum sesuai, bagian mana yang perlu diperbaiki, ditingkatkan atau diubah agar tujuan program tercapai sesuai dengan yang diinginkan.

Evaluasi proses pada program pusat sumber pendidikan inklusif adalah untuk mengetahui sejauhmana program telah berjalan khususnya berkaitan dengan perencanaan, pelaksanaan, dan evaluasi kegiatan program pusat sumber yang sedang berlangsung.

\section{d. Evaluasi Produk (Product)}

$\begin{array}{rrr} & \text { Evaluasi } & \text { produk adalah } \\ \text { evaluasi } & \text { yang } & \text { bertujuan untuk }\end{array}$ mengukur, menginterpretasikan, dan menilai pencapaian program. Evaluasi ini digunakan sebagai bahan pertimbangan menolong keputusan selanjutnya, hubungan dengan konteks, masukan dan proses dan kemudian diinterpretasikan harga dan jasa yang diberikan (Stufflebeam \& Madaus, 2000)

Jadi pada evaluasi produk dalam penelitian ini dilihat sisi sikap guru sekolah inklusif setelah mendapatkan bimbingan, konsultasi maupun pelatihan dari pusat sumber pendidikan inklusif terhadap anak berkebutuhan khusus dan terhadap pendidikan inklusif.

e. Evaluasi

(Outcome)

Evaluasi dampak/keluaran

merupakan evaluasi dampak dari pelaksanaan suatu program, yang diketahui setelah penerima atau sasaran program memanfaatkan hasil yang diperolehnya. Evaluasi outcome pada dasarnya merupakan suatu jenis evaluasi yang menggunakan hasil atau ukuran yang ditetapkan oleh suatu lembaga atau perorangan, untuk digunakan sebagai rujukan evaluasi (krieteria) dalam menentukan sejauh mana tingkat kebehasilan program tersebut (Shen, 2020). Evaluasi dampak/keluaran merupakan efek atau dampak dan manfaat serta harapan 
perubahan dari suatu sebuah kegiatan atau pelayanan suatu program. Menurut Rohmatulloh \& Imam Shalahuddin (2016) evaluasi dampak/keluaran merupakan hasil dari berfungsinya evaluasi produk (output). Outcome bukan aktivitas atau program itu sendiri, melainkan dampak langsung yang dirasakan peserta baik berupa perubahan tingkat pemikiran, sikap, perbuatan maupun prestasi lebih tinggi. Pada penelitian ini, evaluasi dampak/keluaran yang diharapkan dalam program pusat sumber adalah pelaksanaan pembelajaran bagi anak berkebutukan khusus yang dilakukan oleh guru sekolah inklusif.

\section{Kriteria keberhasilan}

Evaluasi konteks yang meliputi: regulasi atau landasan hukum, analisis kebutuhan, sasaran program. Kebijakan atau regulasi yang berkaitan dengan pusat sumber pendidikan inklusif sehingga pelaksanaan program pusat sumber pendidikan inklusif memiliki landasan hukum yang jelas, analisis kebutuhan. Analisis kebutuhan untuk melihat kebutuhan-kebutuhan mungkin yang belum terdapat dalam program sehingga bisa dijadikan masukan dalam perbaikan program yang selanjutnya. Evaluasi sasaran program untuk melihat apakah program telah dilakukan memenuhi kesesuain antara sasaran program pusat sumber pendidikan inklusif dengan pihak stakeholder.

Evaluasi Input yang meliputi: Kesiapan SDM dalam mendukung pelaksanaan program pusat sumber pendidikan inklusif. Setiap SLB yang ditunjuk menjadi pusat sumber pendidikan inklusif memiliki program yang jelas dan terukur tingkat keberhasilannya; Kesiapan dana (biaya), lembaga pusat sumber didukung dengan anggaran yang jelas dan membuat variabel aksi pendidikan inklusif dalam RAKS; adanya kerjasama dengan sekolah inklusif yang bersifat kemitraan dan partnership.

Evaluasi proses telihat dari terlaksananya proses layanan pendidikan, terlaksanannya layanan guru pendamping khusus, berfungsinya sarana prasarana untuk mendukung kegiatan pusat sumber pendidikan inklusif, terlaksanan pelatihan tentang pendidikan inklusif bagi guru dan tenaga pendidikan pada sekolah inklusif serta adanya evaluasi bersama pelaksanaan program pusat sumber pendidikan inklusif; evaluasi produk, dilihat dari sikap guru sekolah inklusif terhadap pendidikan inklusif; dan evaluasi outcome pelaksanaan pembelajaran bagi anak berkebutuhan khusus di sekolah inklusif.

Dalam pengumpulan data, penelitian ini menggunakan empat jenis instrument, yaitu: studi dokumentasi, wawancara, observasi, dan angket yang terbagi dalam lima komponen evaluasi, yaitu: konteks, masukan, proses, hasil dan dampak/keluaran.

Teknik analisis data yang akan digunakan dalam penelitian ini adalah analisis kualitatif dan deskriptif kuantitatif. Analisis kuantitatif dengan mendeskripsikan dan memaknai data dari masing-masing komponen yang dievaluasi, dan hasil perhitungan statistik deskriptif disajikan dalam bentuk tabel frekuensi dan persentase yang didapat dari hasil penelitian.

\section{METODE PENELITIAN}

Secara umum penelitian ini bertujuan untuk mengetahui efektifitas dan keberhasilan program pusat sumber 
pada sekolah luar biasa yang ditunjuk oleh Dinas Pendidikan DKI Jakarta sebagai Pusat Sumber. Penelitian ini dilaksanakan pada sekolah luar biasa yang ditunjuk sebagai lembaga pendidikan yang menyelenggarakan program pusat sumber pendidikan inklusif di wilayah DKI Jakarta. Penelitian ini menggunakan penelitian evaluatif, dengan metode campuran atau mixed-methods research antara kualitatif dengan kuantitatif. Model evaluasi menggunakan Model CIPPO.

\section{Desain Evaluasi}

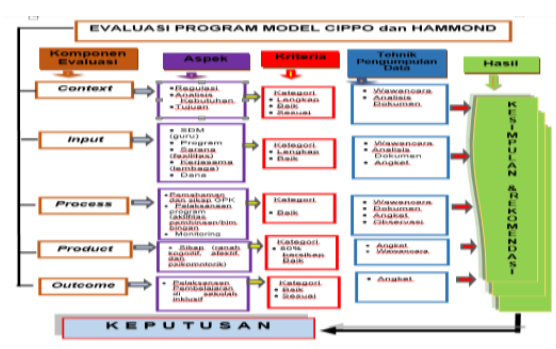

Gambar. 1 Desain Evaluasi Program Pusat Sumber Pendidikan Inklusif Kombinasi Model CIPPO

\section{HASIL DAN PEMBAHASAN \\ 1. Komponen Konteks}

Komponen konteks terdiri dari tiga aspek yaitu: regulasi program, analisis kebijakan dan kesesuaian tujuan dengan sasaran program. Regulasi atau kebijakan yang memayungi program pusat sumber pendidikan inklusif secara internasional, nasional maupun daerah telah sesuai dengan kriteria evaluasi. Artinya bahwa pelaksanaan program pusat sumber pendidikan inklusif telah mengacu pada regulasi atau kebijakan. Regulasi secara internasional program pusat sumber mengacu pada Declaration of Human Right 1948, Convention on the Rights of the Child 1989, resolusi PBB No 48/96 tahun 1993, Deklarasi
Salamanca (UNESCO, n.d.)

Konferensi Dakar tahun 2000. Regulasi secara nasional mengacu pada Undang Undang Dasar 1945, Undang-undang Nomor 20 tahun 2003 tentang Sistem Pendidikan Nasional, Peraturan Daerah Propinsi DKI Jakarta Nomor 8 tahun 2006 tentang Sistem Pendidikan, Surat keputusan Nomor 273/2012 Tentang Penunjukkan Pusat Sumber Pendidikan Inklusif Provinsi DKI Jakarta. Pada Surat Keputusan Nomor 273/2012 ini jumlah Sekolah Luar Biasa (SLB)/Lembaga di DKI Jakarta ditunjuk menjadi Pusat Sumber Pendidikan Inklusif menjadi 21 Sekolah/Lembaga.

Aspek analisis kebutuhan telah sesuai kebutuhan dan terdapat analisis kebutuhan. Program pusat sumber pendidikan inklusif merupakan program yang sangat dibutuhkan oleh sekolah penyelenggara pendidikan inklusif. Kegiatan-kegiatan yang mendukung program berdasarkan hasil analisis antara pihak pusat sumber dengan pihak sekolah penyelenggara pendidikan inklusif. Adanya kesesuaian antara tujuan dan sasaran dengan program pusat sumber pendidikan inklusif dengan pihak stakeholder.

Jadi, hasil evaluasi menunjukkan bahwa evaluasi komponen context semua aspek telah memenuhi kriteria yaitu program pusat sumber pendidikan inkluisf telah mengacu pada regulasi yang ada, sesuai dengan analisis kebutuhan dan adanya kesesuaian antara tujuan dan sasaran dengan program pusat sumber pendidikan inklusif.

2. Komponen Masukan 
Hasil evaluasi menunjukkan bahwa evaluasi komponen input belum semua aspek memenuhi kriteri, aspek yang telah memenuhi kriteria yaitu: kesiapan SDM, kesiapan program, kesiapan sarana, dan kelengkapan administrasi. Kelengkapan administrasi yang belum memenuhi criteria pada sub aspek struktur organisasi, sedangkan aspek kesiapan dana belum memenuhi kriteria karena belum adanya dukungan financial yang memadai.

3. Komponen Proses

Komponen proses, berdasarkan evaluasi hanya proses layanan pendidikan bagi anak berkebutuhan khusus yang memenuhi kriteria, guru pembimbing khusus telah melakukan palayanan pendidikan terhadap anak berkebutuhan khusus mulai dari asesmen, membuat program pembelajaran secara individu dan layanan pembelajaran. Untuk aspek layanan pendampingan dan konsultatif terhadap guru sekolah inklusif dan sosialisasi pelaksanaan program pusat sumber belum sepenuhnya memenuhi kriteria karena guru sekolah penyelenggara pendidikan inklusif lebih menyerahkan proses pembelajaran bagi anak berkebutuhan khusus untuk ditangani oleh guru pembimbing khusus. Untuk monitoring dan evaluasi belum dilakusanakan dengan baik dan kontinyu.

4. Komponen Hasil

Komponen hasil atau produk yaitu Sikap guru terhadap pendidikan inklusif (ranah kognitif, afektif dan psikomotor) telah memenuhi kriteria dengan $100 \%$ guru sekolah penyelenggara pendidikan inklusif telah bersikap positif terhadap pendidikan inklusif.
5. Komponen Keluaran

Komponen keluaran atau outcome berkaitan dengan Pelaksanaan pembelajaran bagi $\mathrm{ABK}$ di sekolah inklusif oleh guru sekolah penyelenggara pendidikan inklusif. Pada komponen keluaran dapat dikatakan memenuhi kriteria jika $80 \%$ dengan kategori baik. Hasil evaluasi menunjukkan bahwa komponen keluaran belum memenuhi kriteria. Pada aspek perencanaan pembelajaran $69 \%$ kategori belum baik, aspek pelaksanaan pembelajaran $55,38 \%$ kategori belum baik dan aspek evaluasi 70,77 \% kategori belum baik.

\section{KESIMPULAN}

Hasil menunjukkan bahwa: (1) komponen context, seluruh aspek dan indikator telah memenuhi kriteria; (2) komponen input belum semua aspek memenuhi kriteri (3) komponen process belum semua aspek memenuhi kriteria; (4) komponen product telah memenuhi kriteria; dan (5) komponen outcome belum memenuhi kriteria. Jadi dapat disimpulkan bahwa program pusat sumber pendidikan inklusif belum berjalan dengan baik.

\section{DAFTAR PUSTAKA}

Brinkerhoff, R. O., \& et. Al. (1983).

Program Evaluation; A

Practutioner's guide For Traines

and Educatosr. Kluwe-Nijhoof

Publishing.

Dunn, W. N. (2008). Public Policy Analysis: An Introduction. Pearson.

Kemdikbud. (2014). Laporan Akuntabilitas Kinerja Instansi Pemerintah (LAKIP) Dirje Kemdikbud 2014. Laporan Akuntabilitas Kinerja Instansi Pemerintah (LAKIP) Dirjen 
Kemdikbud 2014, 1-266.

Kirkpatrick, L. A. (2005). Attachment, Evolution, and the Psychology of Religion. The Guilford Press.

Mastropieri, M. A., \& Scruggs, T. E. (2010). The Inclusive Classroom:

Strategies for Effective

Diffrentiated Instruction. New Jersey: Merril Upper Saddle River.

Okongo, R. B., Ngao, G., Rop, N. K., \& Nyongesa, W. J. (2015). Effect of Availability of Teaching and Learning Resources on the Implementation of Inclusive Education in Pre-School Centers in Nyamira North Sub-County, Nyamira County, Kenya. Journal of Education and Practice, 6(35), 132-141.

http://ezproxy.library.yorku.ca/logi n?url=http://search.proquest.com/d ocview/1773227117? accountid=15 182

Rohmatulloh, -, \& Imam Shalahuddin, M. (2016). Pengembangan Model Logika Evaluasi Program Pengembangan Sdm Responsif Gender Bidang Esdm. Jurnal Teknik Industri, 15(2), 145. https://doi.org/10.22219/jtiumm.vo 115.no2.145-153

Shen, L. C. (2020). The Effeminate Boy and Queer Boyhood in Contemporary Chinese Adolescent Novels. Children's Literature in Education, 51(1), 63-81. https://doi.org/10.1007/s10583018-9357-7

Stufflebeam, D. L. Shinkfield, A. J. (2007). Evaluation theory, models and applications. CA: Jossey-Bass. Stufflebeam, D. L., \& Madaus, G. F. (2000). Evaluation Models : Viewpoints on Educational and Human Service Evaluation (T. Kellaghan (ed.)). Springer. 